\title{
DIGITIZATION OF CULTURAL HERITAGE BUILDINGS FOR PREVENTIVE CONSERVATION PURPOSES
}

\author{
MARIA-GIOVANNA MASCIOTTA ${ }^{{ }^{*}}$, LUIS SANCHEZ-APARICIO ${ }^{2,3}$, \\ SUZY BISHARA ${ }^{4}$, DANIEL V. OLIVEIRA ${ }^{4}$, DIEGO GONZALEZ-AGUILERA ${ }^{3}$ AND \\ JOAQUIN GARCIA-ALVAREZ ${ }^{5}$
}

$1 *$ Department of Engineering and Geology (INGEO)

"G. d'Annunzio" University of Chieti-Pescara

Viale Pindaro 42, 65127 Pescara, Italy

e-mail: g.masciotta@unich.it_*corresponding author)

${ }^{2}$ Department of Construction and Technology in Architecture (DCTA)

Escuela Técnica Superior de Arquitectura de Madrid (ETSAM), Universidad Politécnica de Madrid

Av. Juan de Herrera 4, 28040 Madrid, Spain e-mail: lj.sanchez@upm.es

${ }^{3}$ Department of Cartographic and Land Engineering University of Salamanca, Higher Polytechnic School of Ávila

Hornos Caleros 50, 05003 Avila, Spain

e-mail: luisj@usal.es; daguilera@usal.es

${ }^{4}$ Department of Civil Engineering

ISISE, University of Minho

Campus de Azurém, 4800-058 Guimarães, Portugal

e-mail: suz.bishara@gmail.com; danvco@civil.uminho.pt

${ }^{5}$ Fundación Santa María la Real del Patrimonio Histórico

Aguilar de Campoo, Palencia, Spain

e-mail: j.garcia@santamarialareal.org

Keywords: Historical Constructions, Preventive Conservation, Digital Documentation, Geospatial Database, PlusCare System, Internet of Things

\begin{abstract}
This work aims at presenting the experimental results obtained by the application of one of the digital protocols developed during the European project HeritageCare: Monitoring and preventive conservation of historical and cultural heritage. These protocols are devoted to the preventive conservation of heritage constructions and its assets. More specifically, the application of the second level of services of the HeritageCare system is presented through two complementary case studies: a large Neo-Manueline church situated nearby Guimarães, Portugal, and a small Romanesque church located in Palencia, Spain. In each case study a different set of digital technologies was employed with the aim of evaluating the flexibility of the developed protocols. This set of technologies comprises the use of in-house
\end{abstract}


apps for enhancing the visual inspection together with geomatic techniques based on static and wearable laser scanners as well as digital single-lens reflex and as-built $360^{\circ}$ cameras. The results obtained by the application of these digital tools have allowed the creation of a WebGIS platform for ensuring the proper documentation of cultural heritage and streamlining the management of their conservation process according to a proactive approach.

\section{INTRODUCTION}

Built heritage is the most important physical evidence of the cultural development and diversity of the humankind. It reflects the historical layers of our society, encompassing various construction systems and materials as well as a wide range of structural typologies, such as cathedrals, palaces, castles, and dwellings, among others. Although representing a significant part of our built environment, following the second world war the maintenance of heritage structures has been set aside in favor of the exponential growth of new constructions, thus increasing their potential for structural damage. Last disasters have demonstrated that there is a clear mismatch between budget spent on constructions or large reactive restorations and budget invested on maintenance. The key to prevent damages and minimize deterioration processes is to adopt a proactive conservation strategy, which means replacing belated and overpriced interventions with timely and affordable condition-based maintenance actions. To be effective and sustainable in the long-term, such an approach must be rooted in systematic documentation and monitoring routines and must be supported by optimized digital workflows that can guarantee the heterogeneous informatic the European project cultural heritage" (SOE level system of services heritage in Southwestem Europe. By leveragit
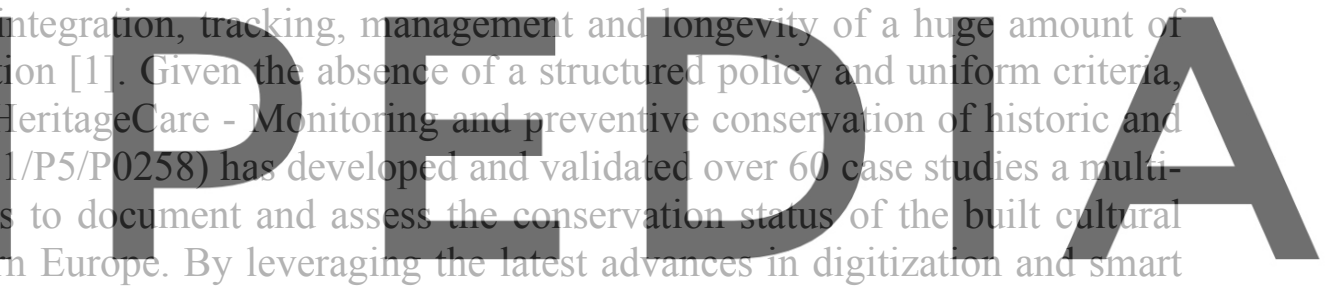
technologies, this system employs standardized yet flexible data collection protocols

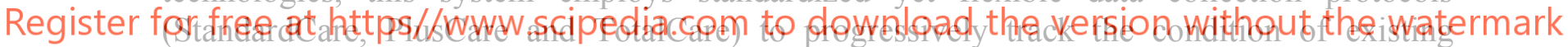

heritage and store baseline information for future comparative analysis [2]. In line with the European standards relevant to this field [3], [4], [5], the HeritageCare methodology aims to streamline the conservation process of historical buildings, whether listed or not, by helping the respective owners and managers minimize or prevent damages in their properties with the scheduling of priority-based maintenance actions [6], [7].

The focus of this paper is to present one of the protocols (PlusCare) developed during the HeritageCare project and related Web-GIS tool in order to show the potentialities offered by the combination of Virtual Reality (VR), Internet of Things (IoT) and Geographic Information Systems (GIS) in the field of preventive conservation of cultural heritage and highlight the advantages brought by the digital revolution in capturing, managing and processing "big-data" within a tolerable time from virtually anywhere in the world. To this end, after a brief description of the HeritageCare system and related documentation protocols, the paper discusses the application of the PlusCare tool to two representative case studies selected among the great variety of heritage structures located in South-West Europe: a large Neo-Manueline church situated nearby Guimarães, Portugal, and a small Romanesque church located in Palencia, Spain. 


\section{A DIGITAL-BASED SYSTEM FOR HERITAGE DOCUMENTATION}

\subsection{HeritageCare integrated protocols}

The HeritageCare system is organized in three complementary service levels (SL), hereafter referred as StandardCare, PlusCare and TotalCare, whose main pillar is the systematic inspection and monitoring of the existing built heritage and related indoor assets. The quantity and complexity of the information collected about the conservation state of the inspected items increase along with the sophistication of the tools employed in each level, being progressively stored into a capable database accessible through a web platform.

Particularly, the StandardCare protocol (SL1) aims at providing a low-cost and rapid condition assessment of the inspected heritage building by identifying its main damages and delivering, in the form of an inspection report, essential information about its primary conservation needs. This protocol relies on the use of a mobile inspection app for uploading and retrieving information directly to/from the HeritageCare database, allowing a real-time digitization of the entire inspection process.

On the other hand, the PlusCare protocol (SL2) provides a more extended knowledge of the heritage ensemble by complementing and integrating the information collected during SL1 with an in-depth documentation of the building state, including detailed inspections of indoor assets, high-resolution surveys, monitoring of relevant parameters and recording of any supplementary data that can contribute to increase the level of knowledge about the actual condition of the buildings/assets (Figure protocol relies on a different data sources, users (owners and mante conservation of their bu

Finally, the TotalCare p
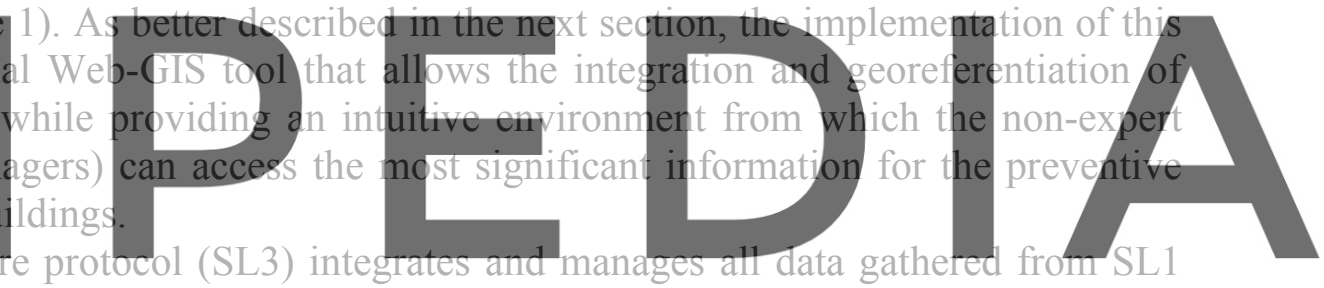
and SL2 through the development of interoperable 3D digital models, representative of the

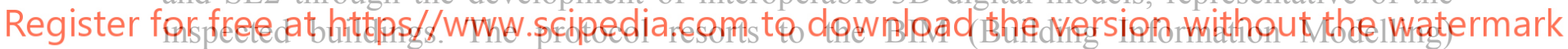
environment to populate these models with meaningful data and attributes concerning the conservation state of the inspected building, allowing to support informed decision-making and to rationalize the management of the heritage conservation process as information can be easily visualized, controlled, shared and updated.

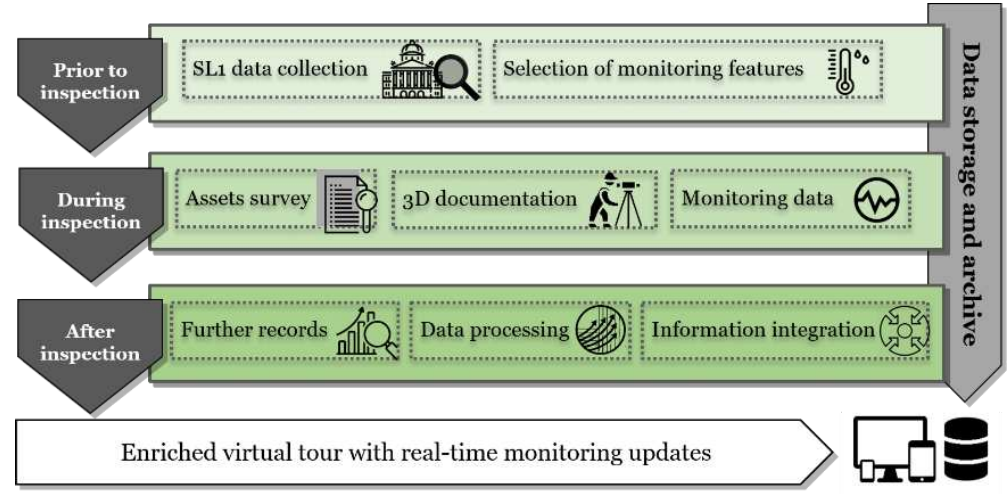

Figure 1: PlusCare protocol of the HeritageCare preventive conservation system. 


\subsection{The PlusCare tool}

The efficient implementation of the PlusCare protocol required the development of a tool able to blend together the latest advances in Virtual Reality (VR), Internet of Things (IoT) and Geographic Information Systems (GIS) in order to integrate and georeference multiple and heterogeneous information coming from different inspection \& diagnosis techniques as well as guarantee protocols interoperability. This resulted into a unique Web-GIS tool called PlusCare system, integral part of the HeritageCare platform. This system converges into a dual webenvironment, namely one for expert users (inspectors) and one accessible by nonexpert users (owners, stakeholders, etc.) upon successful authentication and authorization.

The main functionality of the expert-user environment is to store into specific tabs all the technical information progressively gathered through the application of the PlusCare protocol, namely: assets condition, panorama photos, monitoring data, point clouds, data records and damages. To facilitate the information transfer between technicians and end-users, the nonexpert user environment features a friendly and intuitive interface composed of comprehensive $360^{\circ}$ photos of the inspected building across which the owner/manager can virtually navigate and access all the aforementioned information uploaded by the inspectors and enclosed in the virtual tour in the form of georeferenced hotspots. This graphical interface is complemented by a bottom navigation bar that allows to consult high-resolution geometric data via the 3D point cloud as well as the StandardCare condition report. Additionally, if a monitoring network is installed in the building, the PlusCare system is provided with a communication protocol that

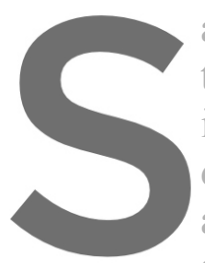
allows to retrieve real-t their acceptability/degre information about the digitized, integrated, supporting tool to source to facilitate screening activities over time.
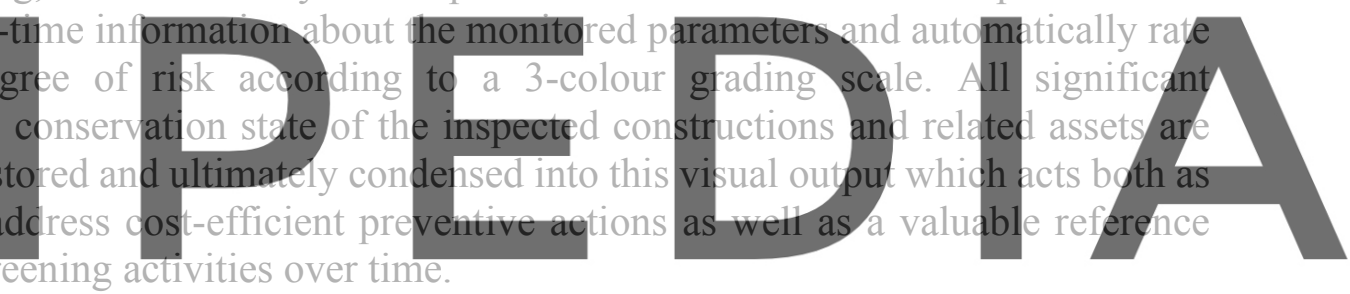

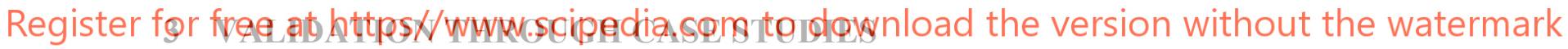

During the project, the HeritageCare protocols and related tools were successfully tested across a notable number of heritage buildings among Portugal, Spain, and Southwestern France. As an example, this section summarizes the application of the PlusCare protocol to two complementary case studies (Figure 2): a large Neo-Manueline church situated nearby Guimarães, Portugal, and a small Romanesque church located in Becerril del Carpio, Palencia, Spain.

\subsection{Church of São Torcato, Portugal}

São Torcato church is a Neo-Manueline style construction located in the homonymous village in Northern Portugal. The architectural form of the church follows the plan of a Latin cross, with a central nave and a transept, each covered with a barrel vault. The North end of the nave ends with an apse, while at the South end is a gallery entrance with a high choir above. Gabled roofs with wooden trusses protect the vaults beneath. A dome laying on an octagonal tambour sits above the main altar, at the crossing between nave and transept (Figure 2). Side chapels extend along the main nave from the transept to the towers that symmetrically frame the façade. The construction of the church began in 1825 to house the body of São Torcato, 
Christian martyr, and stretched over nearly two centuries, involving several building phases. Hence, different materials can be distinguished in the fabric: the walls of towers, nave and transept are made of three-leaf granite masonry with thin mortar joints and inner rubble core, whereas the recently reconstructed dome and apse are made of reinforced concrete (the latter covered with granite veneer).

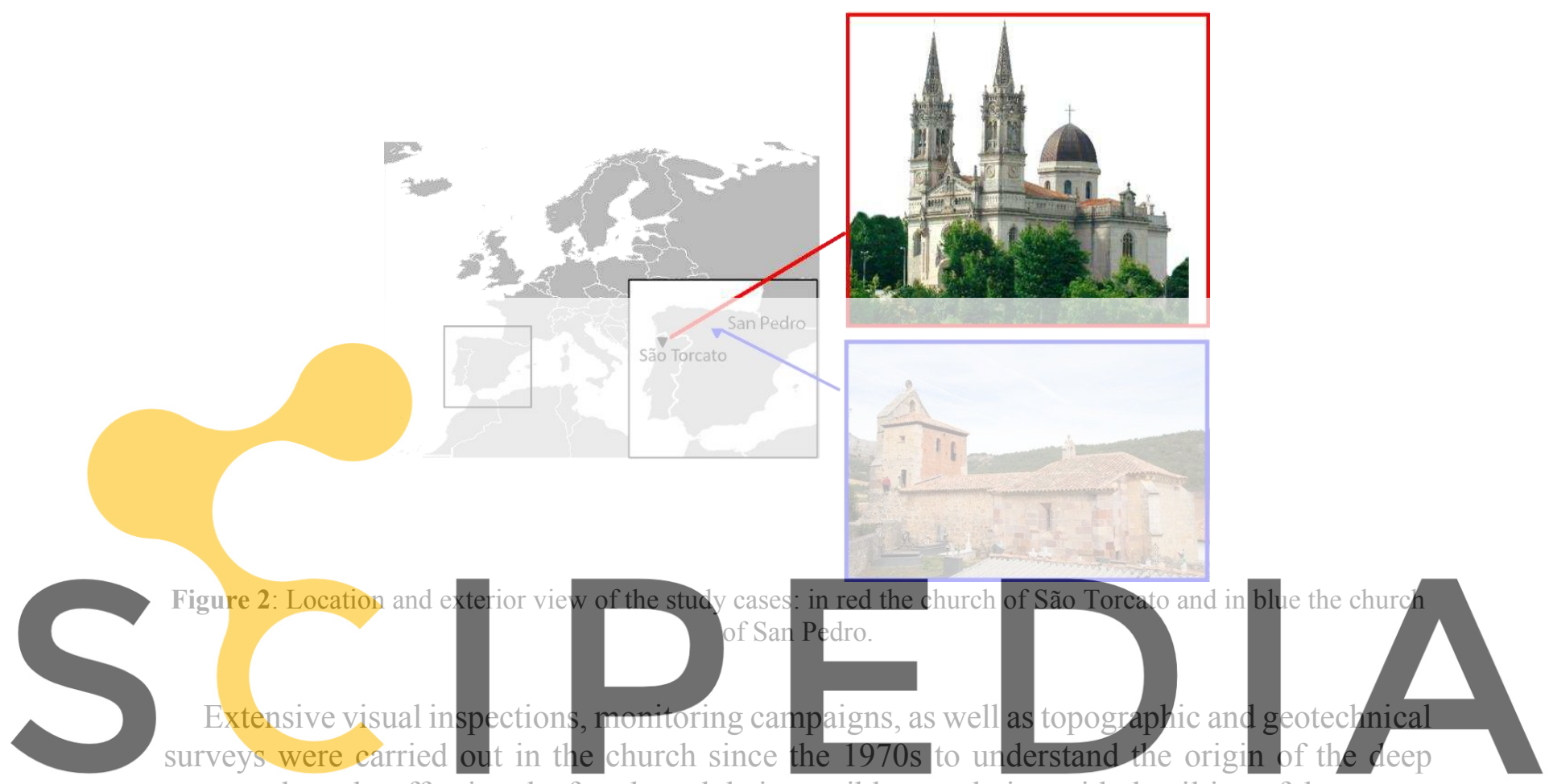

structural cracks affecting the façade and their possible correlation with the tilting of the towers

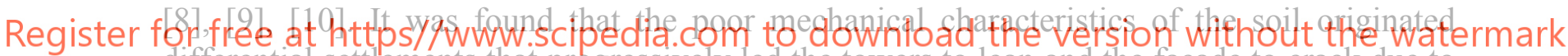
differential settlements that progressively led the towers to lean and the façade to crack due to

the increasing tensile stresses induced by the towers' movement. As the damage was worsening, the church underwent an in-depth intervention (04/2014-07/2015) that involved the installation of micro-piles to eliminate the differential settlements, the placement of post-stressed tie rods to restrain the towers, and the injection of cracks to restore the material continuity. Before, during and after the intervention, the system's response was tracked by means of a monitoring system, which allowed to supervise the progress of the structural consolidation and assess the effectiveness of the strengthening measures [8].

After a documentary research to collect all existent data about the church, including past diagnostic investigations, a systematic inspection was carried out by the HeritageCare team in order to digitally document the conservation status of the construction a few years after the structural intervention previously described. The HeritageCare mobile e-form was exploited to drive the field work and allow a real-time digitization of the inspection process (Figure 3).

Besides the presence of damages not detrimental to the structural integrity, such as efflorescence and biological microorganisms, especially in the form of lichens both on top of the exterior walls and roof tiles, the condition survey revealed problems of bird infestation in the towers and arcade loggia as well as problems of water infiltration through the roof covering, 
walls and openings. Like most of historical stonemasonry structures, the lack of adequate drainage and waterproofing systems played a major role in the development of this type of damages. Surface discolouration processes of diverse nature were also reported on the bottom part of the outer walls of the church. From a structural standpoint, a permanent deformation resulting from the settlements and cracks that affected the church prior to the intervention could be observed in the choir above the entrance. Moreover, new structural cracks were detected on the triumphal arch and along the lateral walls of the nave up to the roof level, pointing out the necessity to install some crack monitoring gauges to understand their actual behaviour and exclude the presence of unstable phenomena. Each damage was accurately documented and assessed according to the HeritageCare damage rating system [1], [6] allowing to identify the primary conservation needs of the church and to assist the owner with the prioritization of remedial measures. To achieve a more detailed knowledge of the building and related indoor assets, this documentation was then integrated by applying the protocol described in Section 2 . For the sake of brevity, only the workflow followed for the $3 \mathrm{D}$ digitization and virtualization of the church is presented next.
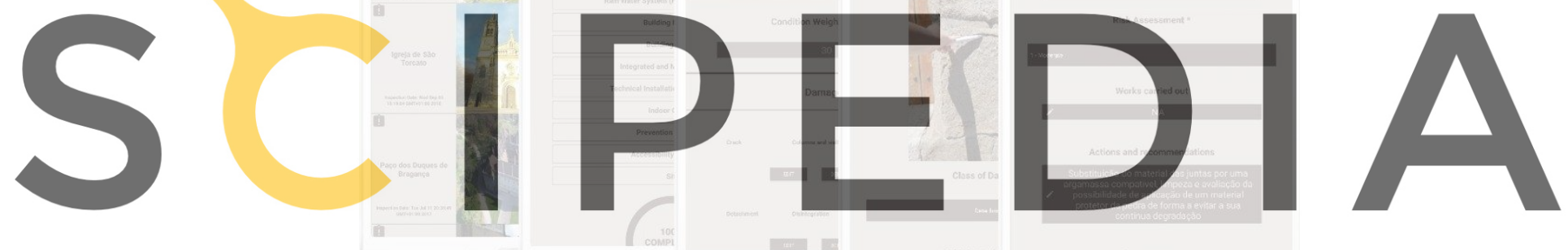

Register for free at https//www.scipedia.com to download the version without the watermark

Figure 3: HeritageCare mobile e-form used to document the onsite inspection.

A laser scanner survey was carried out using a Leica ScanStation P20 in order to obtain highresolution $3 \mathrm{D}$ data for accurate geometrical representation and geo-referenced damage mapping. With a maximum capture rate of 1,000,000 points per second, this tool allowed to collect in one working day millions of points carrying precise volumes of information about exterior and interior of the church, thus constituting a valuable reference source of the current conservation state of the heritage (Figure 4). This 3D model required the work of two technicians during 3 weeks and 174 scan stations, obtaining a 3D point cloud made up by 3 billion of points. Then, this point cloud was reduced by different filters to 17 million of points. In parallel, the as-built $360^{\circ}$ camera Ricoh theta V camera was employed to take $360^{\circ}$ panoramic images both inside and outside. This camera is equipped with two $180^{\circ}$ fish-eye lenses that allow to obtain, in a direct way, a $360^{\circ}$ panorama. About 110 minutes were necessary to capture 42 panoramas for the virtual environment (2-3 minutes per panorama). Both point cloud and photos were stored into the PlusCare system - along with the rest of information collected about the church - and used as imagery input to create an enriched virtual tour by 
means of the low-cost software Pano2VR $\AA$ as well as the in-house plugin HeritageCare4Pano2VR (Figure 5a). This complement allows to use virtual tours for preventive conservation, adding some extra features that can be consulted in Sánchez-Aparicio et al. [2]. Through this visual tool, the owner was given the possibility to interactively navigate across the church and access fundamental information about its current condition (e.g. type and location of damages, assets condition, geometric details, past monitoring records) through predefined hotspots (Figure 5b). It is worth mentioning that each time new data is uploaded to the platform and georeferenced, new hotspots are automatically created inside the virtual tour and linked to the relevant information. Moreover, if a monitoring system is installed, real-time updates of the monitored parameters can be displayed on screen together with the corresponding warning levels to assist the owner in undertaking appropriate condition-based maintenance actions [2].

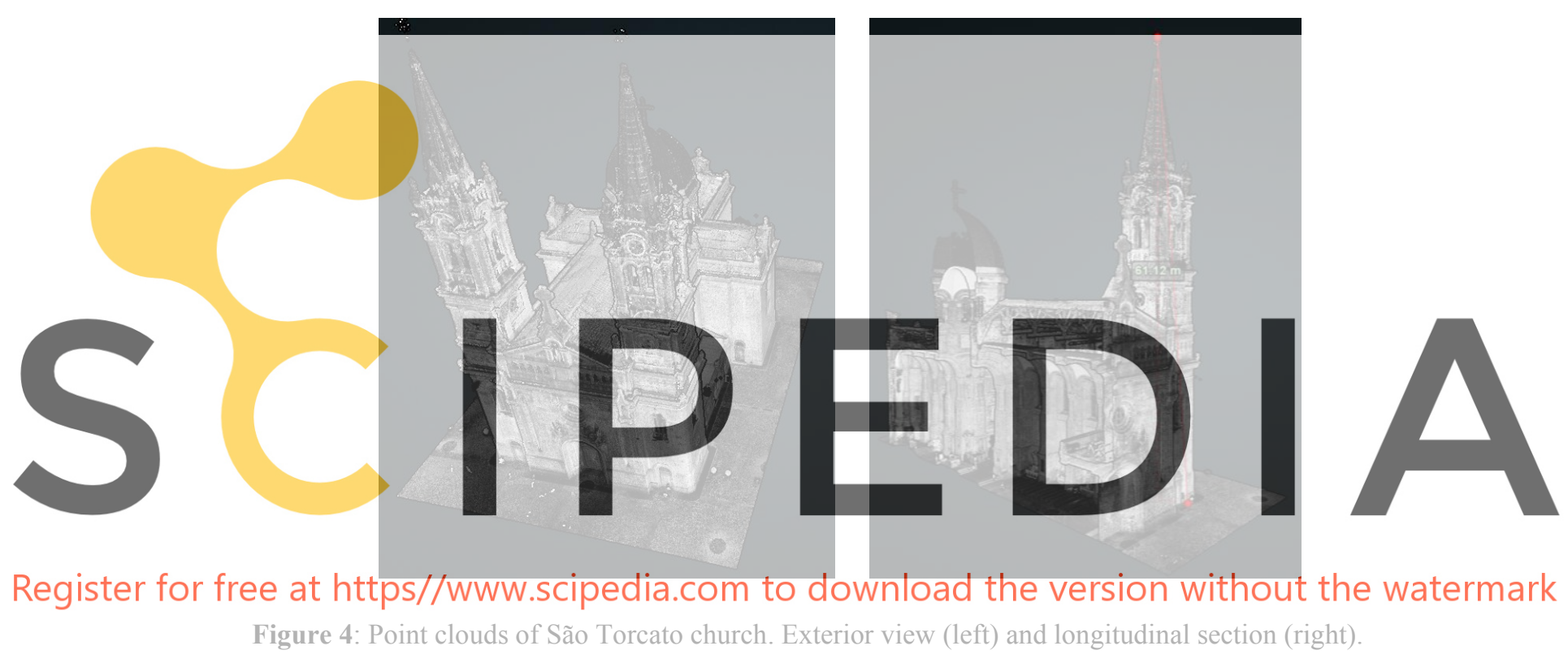

a)

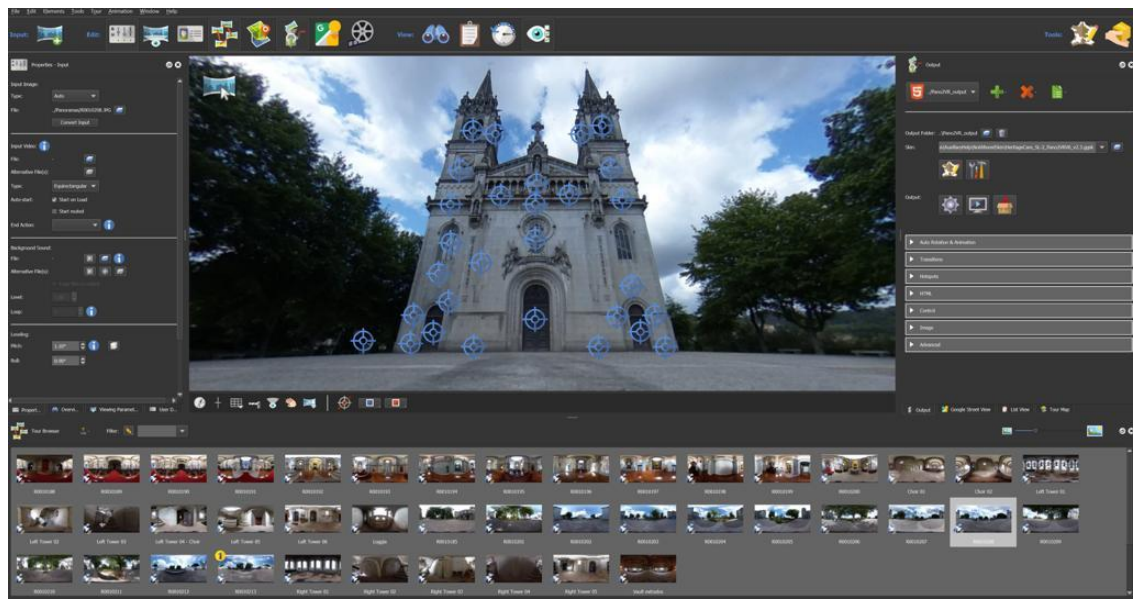


b)

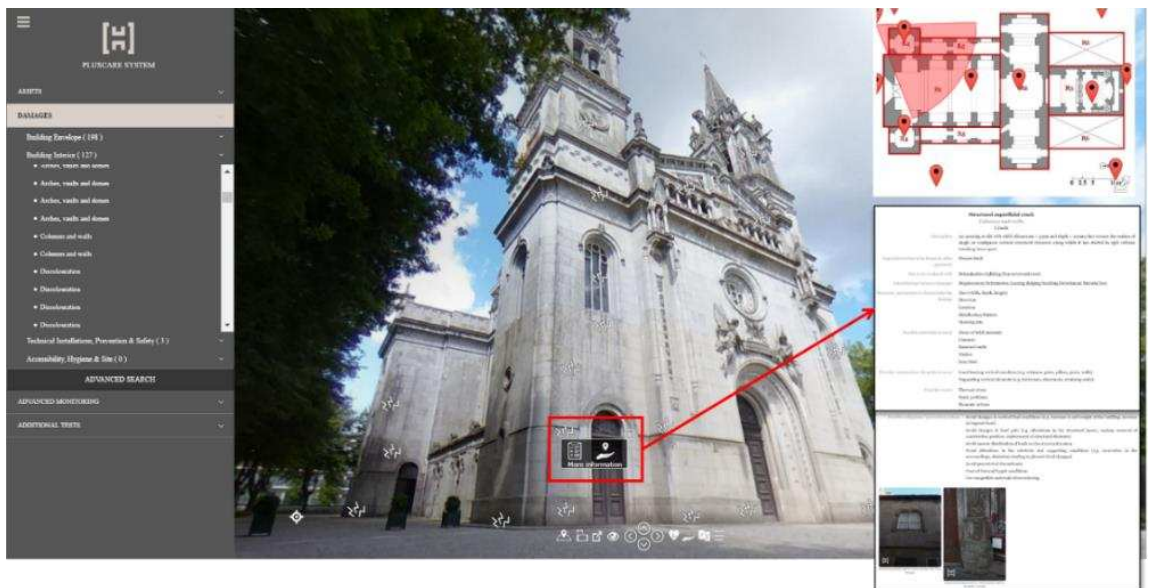

Figure 5: PlusCare system: (a) virtual tour creation through HeritageCare4Pano2VR; (b) final output of São Torcato church.

\subsection{Church of San Pedro in Becerril del Carpio (Palencia), Spain}

The catholic temple of San Pedro is located in the municipality of Becerril del Carpio in Palencia, Spain (Figure 2). This building was originally erected in Romanesque style with a single nave solved by means of a barrel vault, while the apse was erected in Late-Gothic style with a groin vault of eight sides. In the past the church suffered a settlement in the north part of

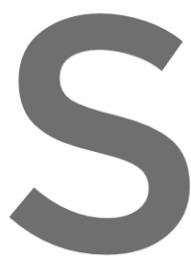
the nave, suffering visit During 2007 an extensi the stability of the struc major restoration took place. foundations placed below the buttresses in ord
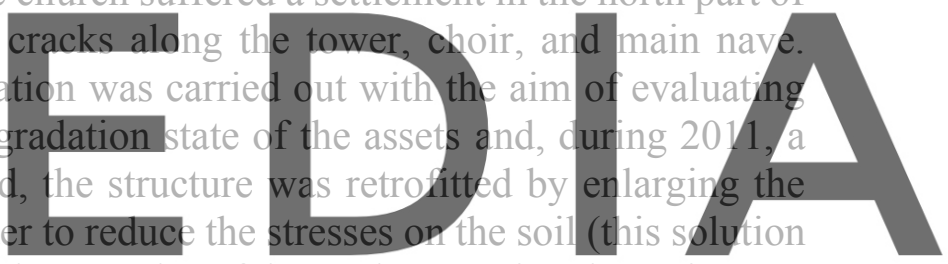

was built in reinforced concrete); additionally, the extrados of the vaults covering the main nave

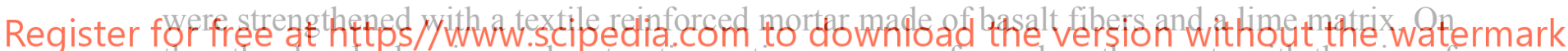
the other hand, cleaning and restoration actions were performed on the assets with the aim of enhancing their understanding and avoiding their impairment and loss of value. However, a preventive conservation protocol that could allow to maintain both the structure and its indoor assets in good conditions was not designed.

Thus, in 2019, the church was included within the policies of the HeritageCare project. In a first stage, the StandardCare protocol was applied; to this end, a technician, supported by a tablet provided with the HeritageCare mobile e-form, performed the inspection of the church following the precepts of this service level. Several issues, related with the main damages affecting the church, were highlighted such as: i) presence of detachments and moisture areas on the south wall of the nave; ii) presence of broken tiles on the roof; and iii) widespread biological colonies (major plants and algae). The use of both HeritageCare damage atlas and damage rating system allowed to classify the observed pathologies in accordance with their nature and relevance. All this information, along with other metadata (e.g. construction period, history of the building, previous interventions, etc.), was properly uploaded to the HeritageCare web platform. The detected damages were also rated according to their associated risk, which were included into an easy-to-read report automatically created by the web platform (Figure 6) and delivered to the owner to assist him in the prioritization of the preventive conservation 
measures. For instance, it was highlighted the necessity of applying specific short-term actions in order to mitigate the water infiltrations in the north part of the nave, including the removal of plants, the change of some windows and ceramic tiles as well as the repair of detachments.

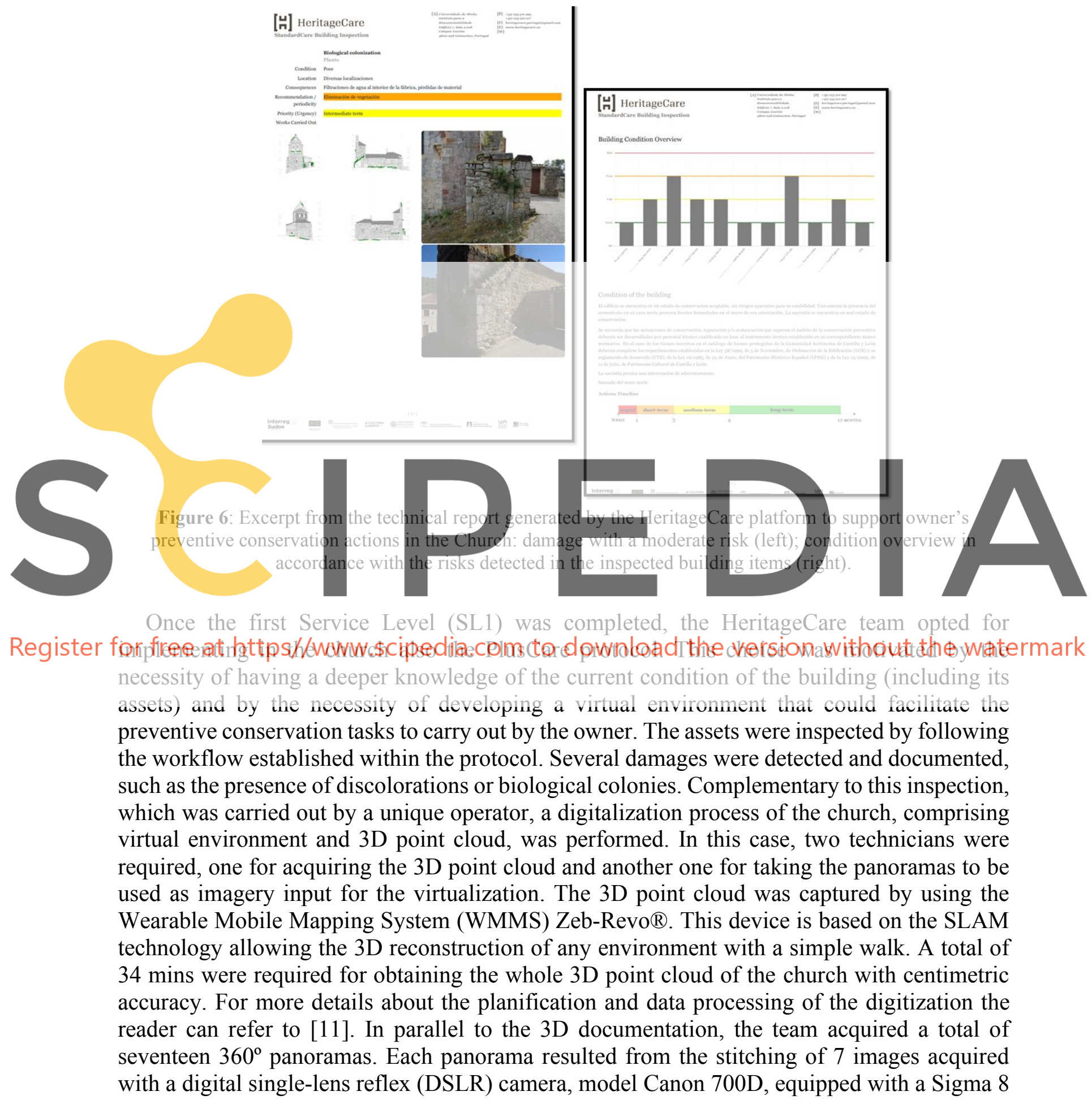


mm F3.5 EX DG fish-eye lens. More details about the data acquisition are given in [12]. The stitching process was carried out in the open-source software Hugin ${ }^{\circledR}$ (http://hugin.sourceforge.net/), investing a total of 9 minutes per panorama ( 2 min for data acquisition and $7 \mathrm{~min}$ for processing). Finally, the panoramas were used to generate an enriched virtual tour of the church by employing the same procedure and tools discussed for the case study of São Torcato. Indeed, all the information gathered during the application of this second Service Level (SL2) was uploaded to the HeritageCare server, allowing to output a really intuitive and powerful web-environment based on $360^{\circ}$ panoramas linked to a geospatial database (Figure 7a). This latter was conceived to make advanced consults, enabling to filter the information concerning the conservation status of the church by different criteria such as urgency risk, type of damage, location of the assets, monitored parameter, etc. Apart from this, the platform also allows the consultation of the condition report and a virtual navigation across the $3 \mathrm{D}$ point cloud to visualize in detail geometric information (Figure $7 \mathrm{~b}$ ).

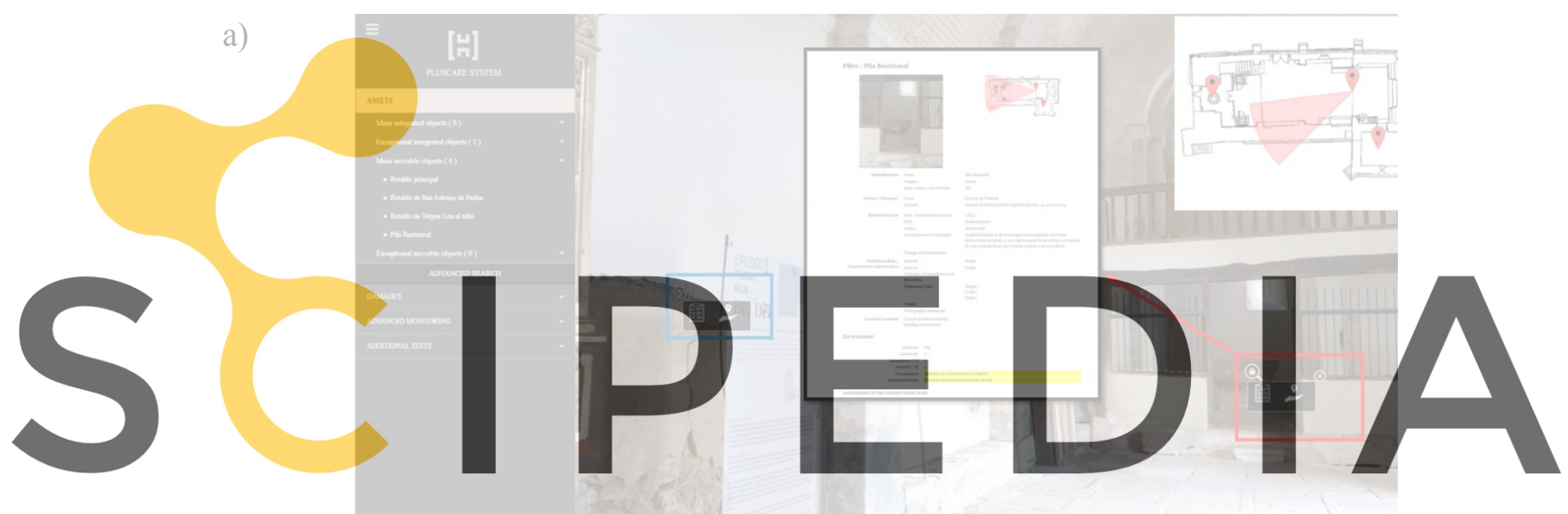

Register for free at https//www.scipedia.com to download the version without the watermark

b)

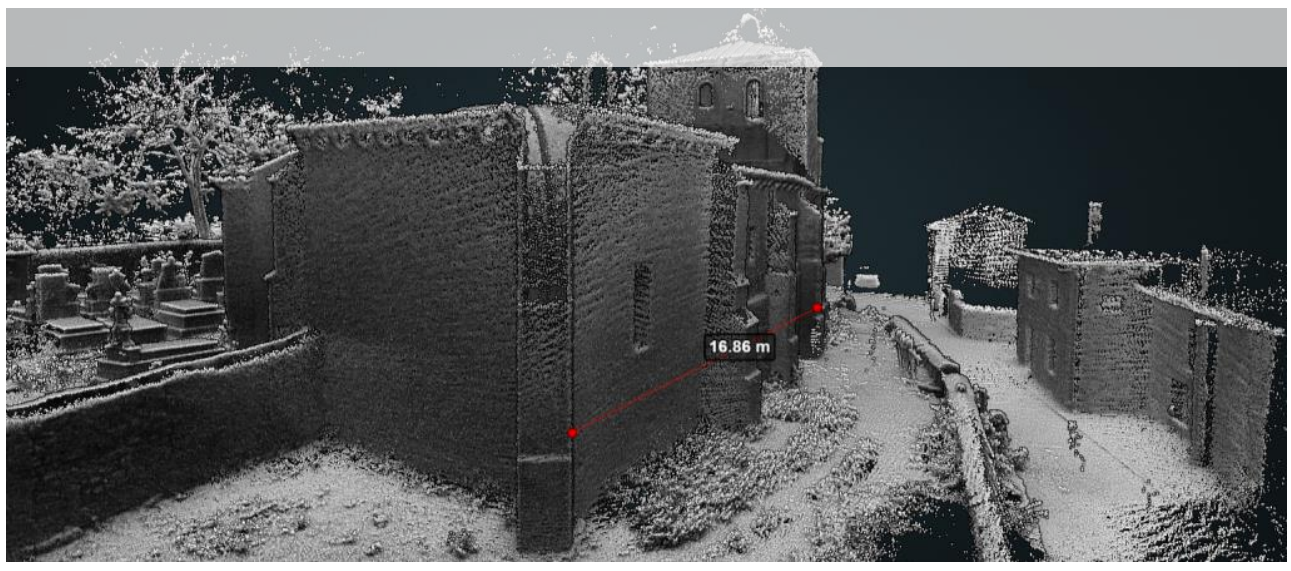

Figure 7: Appearance of the virtual environment created in the PlusCare system: (a) $360^{\circ}$ images linked to the geospatial database; (b) viewer with the metric 3D point cloud of the Church. 


\section{DISCUSSION AND CONCLUSIONS}

This work has presented a digital-based standardized protocol developed within the framework of the European project HeritageCare. More specifically, the digital workflow concerning the second level of services of the HeritageCare preventive conservation system has been discussed in detail. This protocol, called PlusCare, was applied and validated through many case studies in Southwestern Europe, two of which have been reported in this paper to demonstrate the flexibility and scalability of the protocol according to the size and complexity of the heritage object as well as depending on the level of sophistication of the tools used for the digitization process. They are the church of São Torcato in Portugal (medium-size heritage construction) and the church of San Pedro in Spain (small-size heritage construction).

The application of the PlusCare protocol implied the execution of a first level of inspection which was carried out in the same way for both constructions, namely by using the in-house HeritageCare mobile application. This app increases the effectiveness of the onsite inspection work, reducing the time necessary for documenting the observed pathologies and producing a preliminary diagnosis report. In either case, this solution proved to be time-saving in terms of field workload, allowing to document in a few hours the conservation state of each building. With respect to the digitization process featured in the second service level of the HeritageCare system, the current work has shown the application of four different geomatic sensors that can be grouped in two categories: i) the sensor for capturing $360^{\circ}$ images; and ii) a wearable mobile sensor for creating the 3D point cloud of the site. Regarding the former, the results obtained from the validation case studies have highlighted two main advantages of the as-built $360^{\circ}$ cameras that are worth of mentioning: the great efficiency in capturing and processing panoramas in a short period of time (usually between 2-3 mins) as compared to the DSLR camera that demands a total of 9 mins; the high portability in terms of size and weight. In contrast, the DSLR camera offers better radiometric and geometric quality with a deeper control of the image parameters (i.e. aperture, ISO, etc.), property that results particularly relevant in indoor areas characterized by the absence of proper light. Regarding the second digital technology used for capturing the point cloud of the site, the applicative examples have demonstrated that the WMMS provides an efficient solution for the 3D documentation of built cultural heritage. Given the portability of the device, the process requires a temporal window 10 times lower than its static counterpart. However, this sensor has shown some limitations in terms of range, hindering the capturing of high elements such as towers as well as a centimetric accuracy which could be not enough for monitoring structural movements.

This work was financed by ERDF funds through the V Interreg Sudoe program within the framework of the HeritageCare project (Ref. SOE1/P5/P0258). The authors would like to express their gratitude to the Centre for Computer Graphics of the University of Minho for the web implementation of the platform. Authors also acknowledge the continuous support from the São Torcato Brotherhood and the Diocese of Palencia.

\section{REFERENCES}

[1] Masciotta, M.G., Morais, M.J., Ramos, L.F., Oliveira, D.V., Sánchez-Aparicio, L.J., González-Aguilera, D. A digital-based integrated methodology for the preventive conservation of cultural heritage: the experience of HeritageCare project, International 
Journal of Architectural Heritage (2019), DOI: 10.1080/15583058.2019.1668985.

[2] Sánchez-Aparicio L., Masciotta M.G., García-Alvarez J., Ramos L.F., Oliveira D.V., Martín-Jiménez J.A., González-Aguilera D.A. Monteiro P. Web-GIS approach to preventive conservation of heritage buildings, Automation in Construction (2020) 118:103304.

[3] BS EN 15898:2011 Conservation of cultural property - Main general terms and definitions.

[4] UNI EN 16095: 2012 Conservation of cultural property - Condition recording for movable cultural heritage.

[5] UNI EN 16096: 2012 Conservation of cultural property - Condition survey and report of built cultural heritage.

[6] Ramos, L.F., Masciotta, M.G., Morais, M.J., Azenha, M., Ferreira, T., Pereira, E.B., Lourenço, P.B. HeritageCARE: Preventive conservation of built cultural heritage in the South-West Europe, in: Innovative Built Heritage Models, Eds. van Balen, K., Vandesande, A., pp. 135-142, London: CRC Press (2018), ISBN: 9781138498617.

[7] Morais, M.J., Masciotta, M.G., Ramos, L.F., Oliveira, D.V., Pereira, E.B., Azenha, M., Lourenço, P.B., Ferreira, T., Monteiro, P. A proactive approach to the conservation of historic and cultural heritage: the HeritageCARE methodology, in: International Association for Bridge and Structural Engineering Symposium: Towards a Resilience Built Environment - Risk and Asset Management, Guimarães, Portugal. Zurich: IABSE (2019), pp. 64-71, ISBN: 978-3-85748-163-5.

[8] Masciotta, M.G., Ramos, L.F., Lourenço, P.B. The importance of structural monitoring as a diagnosis and control tool in the restoration process of heritage structures: a case-study in Portugal, Journal of Cultural Heritage (2017) 27:36-47.

[9] Sánchez-Aparicio, L.J., Riveiro, B., González-Aguilera, D., Ramos, L.F. The combination of geomatic approaches and operational modal analysis to improve calibration of finite element models: a case of study in Saint Torcato church (Guimarães, Portugal), Construct. Build. Mater (2014) 70:118-129.

[10] Masciotta, M.G., Ramos, L.F., Lourenço, P.B., Matos, J.A.C., Development of key performance indicators for the structural assessment of heritage buildings, in: E-Journal of Non-Destructive Testing - Proc. 8th European Workshop on Structural Health Monitoring (EWSHM 2016), 1 (2016), pp. 606-617, NDT.net.

[11] Sánchez-Aparicio, L.J., Conde, B., Maté-González, M.A., Mora, R., Sánchez-Aparicio, M., García-Álvarez, J., and González-Aguilera, D. A comparative study between MMS and TLS for the stability analysis of the San Pedro Church barrel vault by means of the Finite Element Method, Int. Arch. Photogramm. Remote Sens. Spatial Inf. Sci., XLII2/W15, 1047-1054, https://doi.org/10.5194/isprs-archives-XLII-2-W15-1047-2019, 2019.

[12] HeritageCare. 2017. General methodology for the preventive conservation of cultural heritage buildings. Unpublished document, HeritageCARE (Report of the Project Activity $1.2)$. 